\title{
Body mass index and waist circumference: implications for classifying the prevalence of overweight and obesity in the Royal Navy
}

\author{
A. M. Shaw, D. Simpson, T. Davey and J. L. Fallowfield \\ Institute of Naval Medicine, Alverstoke, Gosport, Hants, PO12 2DL, UK
}

The prevalence of overweight and obesity in the United Kingdom Royal Navy (RN) is increasing ${ }^{(1,2)}$. The consequential health and economic implications of this worrying trend are considerable, and may reduce the physical capability of a force that is required to be "fit to fight". The RN has a duty of care to ensure that all personnel are physically fit and healthy. As such, it is imperative that the RN determines the magnitude of this problem and the most appropriate methods of monitoring any trends over time.

A stratified sample of 600 RN personnel, aged 18-61 years old, consented to participate in the study from fifteen different land bases and two ships. Participants had their height; body mass (from which Body Mass Index (BMI) was calculated), and waist circumference measured at one time point.

Participants with a BMI $\geq 25.0 \mathrm{~kg} \cdot \mathrm{m}^{-2}$ were classified as being overweight or obese and participants with a BMI $<25.0 \mathrm{~kg} . \mathrm{m}^{-2}$ were classified as being a normal weight. BMI in combination with waist circumference measurements were used to classify participants as being at no risk of obesity related diseases, or at any increased risk of obesity related diseases, according to the National Institute for Health and Clinical Excellence (NICE) guidelines $^{(3)}$ (Table below).

\begin{tabular}{|c|c|c|c|c|c|c|}
\hline & \multicolumn{2}{|c|}{ BMI $<25 \mathrm{~kg} \cdot \mathrm{m}^{-2}$} & \multicolumn{2}{|c|}{ BMI $\geq 25 \mathrm{~kg} \cdot \mathrm{m}^{-2}$} & \multicolumn{2}{|c|}{ Total } \\
\hline & $n$ & $\%$ & $n$ & $\%$ & $n$ & $\%$ \\
\hline Males: & & & & & & \\
\hline Waist $<94 \mathrm{~cm}$ & 109 & 35 & 111 & 35 & 220 & 70 \\
\hline Waist $\geq 94 \mathrm{~cm}$ & 0 & 0 & 93 & 30 & 93 & 30 \\
\hline Total & 109 & 35 & 204 & 65 & 313 & 100 \\
\hline Females: & & & & & & \\
\hline Waist $<80 \mathrm{~cm}$ & 161 & 56 & 41 & 14 & 202 & 70 \\
\hline Waist $\geq 80 \mathrm{~cm}$ & 0 & 0 & 85 & 30 & 85 & 30 \\
\hline Total & 161 & 56 & 126 & 44 & 287 & 100 \\
\hline
\end{tabular}

According to the BMI measurements a total of $65 \%$ and $44 \%$ of male and female participants, respectively, were classified as being overweight or obese. In comparison, when the NICE risk classification guidelines were applied, a total of $30 \%$ of both male and female participants were classified as being at any increased risk of obesity related diseases.

When comparing the differences in the present study between the two different methods of classifying participants 'at risk', the BMI method rated males $35 \%$ higher and females $14 \%$ higher, in comparison with the NICE risk classification method. Thus, BMI may be an inappropriate method of measuring adiposity in the RN. These findings highlight the importance of using BMI in combination with waist circumference measurements to classify risk, which supports the current measurement guidelines in the Armed Forces Weight Management Policy ${ }^{(4)}$.

The high prevalence of participants being classified 'at risk' is of concern in a force that is required to be physically fit and healthy. This emphasises the requirement for health promotion activities to modify the eating and physical activity behaviours of RN personnel to improve health and to reduce the prevalence of overweight and obesity.

1. Allsopp A, Scarpello E, Andrews S et al. (2003) J Roy Nav Med Serv 89(1), 11-18.

2. Dziubak A, House C, Taylor R et al. (2011) Institute of Naval Medicine Report 2011.042.

3. National Institute for Health and Clinical Excellence. (2010) CG43.

4. Ministry of Defence. (2009) 2009DIN01-181. 